\title{
POLÍTICAS DE COTAS NAS INSTITUIÇÕES FEDERAIS DE ENSINO SUPERIOR DO RIO GRANDE DO SUL: AVALIAÇÃO DA TRANSPARÊNCIA ATIVA E PASSIVA
}

\author{
http://dx.doi.org/10.5902/2318133843335
}

\author{
Itiane Vanessa Adamski ${ }^{1}$ \\ Monize Sâmara Visentini² \\ Darlan Nei Writzl ${ }^{3}$
}

\begin{abstract}
Resumo
Neste texto apresenta-se resultados de um estudo que teve como objetivo analisar a transparência ativa e passiva da informação relacionada às políticas de cotas nos sites das instituições federais de ensino superior do Rio Grande do Sul. Para realizar a coleta e análise dos dados nos sites na transparência ativa utilizou-se o método de análise de conteúdo. Para a coleta e análise dos dados da transparência passiva foram elaboradas três perguntas e enviadas para as instituições federais de ensino superior pelo e-sic. Os resultados da análise da transparência ativa e passiva da informação referente às políticas de cotas indicam que as dez instituições federais de ensino superior disponibilizam informações sobre as políticas de ingresso, matrícula e permanência de estudantes nessas instituições de forma clara e acessível, procurando atender à Lei de Acesso à Informação.

Palavras-chave: educação pública; lei de aceso à informação; checklist.
\end{abstract}

\section{QUOTA POLICIES IN THE FEDERAL EDUCATION INSTITUTIONS OF RIO GRANDE DO SUL: ASSESSMENT OF ACTIVE AND PASSIVE TRANSPARENCY}

\section{Abstract}

The study aimed to analyze the active and passive transparency of information related to quota policies on the websites of the federal education institutions of Rio Grande do Sul. To perform the collection and analysis of data on the websites on active transparency, we used the content analysis method. For the collection and analysis of passive transparency data, three questions were prepared and sent to federal education institutions by e-sic. The results of the analysis of the active and passive transparency of information regarding quota policies indicate that the ten federal education institutions provide information on the policies for the admission, enrollment, and permanence of students in these institutions in a clear and accessible way, seeking to meet the requirements imposed by the Access to Information Act.

Key-words: public education; information access law; checklist.

\footnotetext{
${ }^{1}$ Universidade Federal da Fronteira Sul, campus Cerro Largo, Brasil. E-mail: itianeadamski@hotmail.com.

2 Universidade Federal da Fronteira Sul, campus Cerro Largo, Brasil. E-mail: monize.visentini@uffs.edu.br.

3 Universidade Federal da Fronteira Sul, campus Cerro Largo, Brasil. E-mail: darlan.writzl@outlook.com. 


\section{Introdução}

om vistas a garantir os direitos humanos, de forma que todos pudessem ser vistos e tratados de maneira equitativa na sociedade, foram criadas as políticas públicas, que são programas de ações governamentais e estão vinculadas diretamente à formação do Estado social. Elas sã voltadas para atender as necessidades relevantes da sociedade, podendo ser caracterizadas também como metas coletivas conscientes (Bucci, 2006).

As políticas públicas devem ser de conhecimento de todos e transparentes. Com isso, em 18 de novembro de 2011, entrou em vigor a lei n. 12.527, denominada Lei de Acesso à Informação - LAI -, que trata do acesso às informações públicas ditas e tratadas no governo (Silva; Hoch; Righi, 2013). Por meio dela regulamentou-se o direito constitucional de acesso às informações públicas, determinando que as instâncias governamentais devem apresentar as informações de interesses particulares e coletivos (Soares; Jardim; Hermont, 2013).

No art. $10^{\circ}$ da LAI prevê-se que qualquer interessado poderá enviar pedido de obtenção de informações aos órgãos e entidades citados no art. 1ํ desta lei, por qualquer meio regular, devendo o pedido incluir a identificação do solicitante e a especificação da informação requisitada, estabelecendo mecanismos de transparência passiva. Assim, na transparência passiva, o Estado divulga ou disponibiliza as informações somente quando solicitado por pessoas físicas ou jurídicas. Sendo assim, é dever do Estado divulgar informações sobre todos os aspectos, como programas educacionais, de distribuição de renda e auxílios financeiros, de ações afirmativas, entre outros assuntos relacionados à população em geral (CGU, 2013).

O termo ação afirmativa é explicado por Oliven (2007) como um conjunto de políticas públicas para amparar grupos minoritários, em uma determinada sociedade, que tenham sido negligenciados no passado. Tendo isso em vista, em agosto de 2012 foi sancionada a lei n. 12.711, denominada Lei de Cotas, sendo que a mesma dispõe de cotas de ingresso de alunos nas instituições federais de ensino superior - Ifes.

Com base nisso, as Ifes buscaram-se adequar-se às leis e normas relacionadas à transparência de informações e às políticas de inclusão (Rodrigues, 2013). Sendo assim, a pesquisa delimitou-se a partir do seguinte problema: como são conduzidas as ações de transparência ativa e passiva no que se refere às políticas de cotas nos sites das universidades e institutos federais de ensino superior do Rio Grande do Sul? O objetivo foi o de analisar a transparência ativa e passiva da informação relacionada às políticas de cotas nos sites das universidades e institutos federais de ensino superior do Rio Grande do Sul.

Faraco (2015) apresenta o fato de que a transparência da área educacional é fundamental e importante para que os gestores e todos os envolvidos com a administração das universidades e institutos federais possam ter um maior controle e gerenciamento mais eficaz. A transparência estabelece uma relação de confiança entre os órgãos que compõem a educação pública e os usuários desse tipo de serviço que é prestado pelo Estado. O processo educacional deve ser transparente e nele devem constar mecanismos de comunicação com a comunidade, divulgando informações relacionadas às prestações de contas, aos programas governamentais utilizados nas instituições de ensino, às leis e diretrizes usadas como base e ainda, às políticas de 
ingresso e acesso às vagas, como por exemplo, as políticas de cotas e as ações afirmativas, que são políticas públicas governamentais que visam beneficiar a todos com uma educação digna, sendo tratados de forma igualitária, podendo assim, exercer os seus direitos.

Acredita-se que um maior controle social permite uma fiscalização mais eficiente das ações governamentais. Dessa forma, por se tratar de um assunto ainda recente e de interesse tanto para a comunidade acadêmica quanto para estudantes do ensino médio, bem como para seus pais ou responsáveis, as ações afirmativas e políticas de cotas das Ifes devem estar visíveis e claras para todos, de modo que sejam apresentadas de forma transparente e acessível.

Souza e Portes (2011) afirmam que "aproximadamente dois terços das Ifes implantaram políticas/ações afirmativas em benefício dos mais necessitados, principalmente daqueles provenientes das escolas públicas" (p. 536). Dessa forma, o controle e fiscalização social das ações governamentais das entidades públicas instigam aos gestores agirem com maior cautela e rigidez na disposição das informações relacionadas às atividades, bem como aos planos e projetos a serem realizados e às práticas de inclusão social e racial realizadas por essas instituições. Além disso, muitas vezes as informações referentes às políticas públicas de cotas não se encontram em locais acessíveis nos sites das Ifes, dificultando a obtenção dessas informações pelas pessoas.

\section{Política de cotas}

De acordo com Souza (2014), no que diz à temática de cotas, em 3 de julho de 1968 foi criada a lei n. 5.465, a Lei do Boi, que dispunha que as instituições de ensino médio agrícola e ensino superior de Agricultura e Veterinária, sustentados pela União, deveriam destinar $50 \%$ de suas vagas à candidatos agricultores ou filhos destes, proprietário ou não de terras, que vivem na zona rural com suas famílias e $30 \%$ à agricultores ou filhos destes, proprietários ou não de terras, que moram em cidades ou vilas que não tenham estabelecimentos de ensino médio. Sucintamente, essa lei criou reservas de vagas em escolas técnicas de nível médio e superior, voltadas para os cursos de Agronomia e Medicina Veterinária, para candidatos que provassem que possuíam algum tipo de relação com a agropecuária (Magalhães, 2017).

A proposta de cotas surgiu na Universidade de Brasília em 1999, devido a um acontecimento conhecido como "Caso Ari". Arivaldo Lima Alves foi o primeiro aluno negro a entrar no doutorado do Departamento de Antropologia após 20 anos de existência do programa. No primeiro semestre do curso foi reprovado em circunstâncias inaceitáveis em uma matéria obrigatória. Essa reprovação fez com que ele perdesse imediatamente 0 curso de doutorado. Após dois anos Ari conseguiu levar o caso ao Conselho de Ensino, Pesquisa e Extensão da universidade, que reverteu o desligamento.

Assunção, Santos e Nogueira (2018) destacam que em 2003 a UnB lançou um Plano de metas de integração social, étnica e racial. Após a idealização e desdobramento desse plano, em 2004, foi implantada a política de cotas raciais na 
universidade, apresentando como objetivo principal proporcionar acesso mais igualitário para alunos negros em todos os cursos ofertados, sendo que $20 \%$ das vagas eram oferecidas para candidatos autodeclarados pardos ou negros.

Visando impulsionar as ações afirmativas na educação, em 2012, foi sancionada a lei n. 12.711/2012, denominada Lei de Cotas. Pereira, Rodrigues e Guilherme (2010) afirmam que "dentro das ações afirmativas, as políticas de cotas raciais têm a intenção de provocar o resgate de uma dívida social à um segmento da sociedade que, historicamente, vem sendo discriminado" (p. 245). Sendo assim, as políticas de cotas fazem parte das ações afirmativas realizadas e impostas pelo Estado.

As informações referentes às cotas universitárias devem ser transmitidas com clareza pelos órgãos públicos, podendo ser interpretada por todos os usuários, leigos ou não no assunto. Para existir transparência na gestão pública é necessária à disseminação clara e objetiva da informação prestada pelo órgão público, e assim, consequentemente, garantir a recepção correta por parte das pessoas (Faraco, 2015).

De acordo com Rodrigues (2013), as Ifes, sendo considerados órgãos públicos, devem cumprir as exigências de transparência ativa impostas pela lei. A comunicação interna e externa dessas entidades públicas deve atender a todos os requisitos exigidos pelo Estado. As informações devem ser claras, de fácil entendimento e acesso. No caso das Ifes estas devem divulgar informações referentes às suas atividades, projetos de pesquisa, informações financeiras e dados sobre as políticas de acessos e ações afirmativas.

\section{Metodologia}

Foram definidas como população as sete universidades e os três institutos federais do Rio Grande do Sul ${ }^{4}$, visando estudar e compreender os critérios utilizados pelas mesmas com relação à transparência ativa e passiva das informações sobre as políticas de cotas utilizadas por essas Ifes em seus portais eletrônicos. Para a coleta dos dados da transparência ativa foi utilizado o método de análise de conteúdo. Bardin (1977) apresenta a organização da análise em três orientações cronológicas: pré-análise; exploração do material; tratamento, inferência e interpretação dos resultados.

De acordo com Bardin (1977), a fase da pré-análise pode ser considerada a etapa de organização em que são escolhidos os objetos de estudo para serem analisados e são formulados os objetivos e hipóteses que auxiliam na fundamentação final. Sendo assim, para a fase de pré-análise da presente pesquisa, foram acessados os links das Ifes referentes às páginas nas quais se encontram informações de políticas de cotas praticadas pelas instituições, com o intuito de verificar as informações disponíveis nos sites das mesmas.

\footnotetext{
${ }^{4}$ Universidade Federal do Rio Grande do Sul; Universidade Federal de Ciências da Saúde de Porto Alegre; Universidade Federal de Santa Maria; Universidade Federal de Pelotas; Universidade Federal do Rio Grande; Universidade Federal do Pampa; Instituto Federal de Educação, Ciência e Tecnologia do Rio Grande do Sul; Instituto Federal de Educação, Ciência e Tecnologia do Sul-rio-grandense; Instituto Federal Farroupilha; Universidade Federal da Fronteira Sul.
} 
Na segunda fase o material coletado nos sites das lfes referente às políticas de cotas foi impresso e analisado, sendo que as informações relevantes e em comum apresentadas por essas instituições foram destacadas para poder elaborar um checklist de análise dessas políticas no que diz respeito à transparência ativa das informações disponíveis.

A terceira e última etapa da análise de conteúdo para a transparência ativa constituise do tratamento, inferência e interpretação dos resultados. De acordo com Bardin (1977) nessa fase os resultados obtidos são tratados de modo que se tornam significativos e válidos. Com isso esses dados podem servir de base para outras análises, sendo assim, esses resultados apurados e interpretados na análise da transparência ativa serviram como base para a elaboração do método de análise da transparência passiva.

Finalizada a coleta e análise dos dados referentes à transparência ativa, foi realizada a coleta das informações pertinentes à transparência passiva, que foi efetivada por meio do portal da transparência do e-sic, seguindo metodologia da Escala Brasil Transparente (CGU, 2019).

Para a avaliação da transparência passiva foi utilizada a metodologia da EBT $360^{\circ}$, considerada uma ferramenta de monitoramento que analisa a transparência ativa e passiva dos órgãos públicos. Essa metodologia propõe que sejam enviadas três perguntas, por diferentes pessoas, pelo e-sic, ou seja, realizar solicitações de acesso à informação por três usuários diferentes, com questões contendo dúvidas distintas (CGU, 2019).

Foi elaborado um checklist para analisar as respostas de cada Ifes individualmente e assim gerar uma nota final objetivando identificar o percentual de transparência passiva de cada uma e realizar um comparativo final. Utilizou-se também o ranking da transparência das universidades federais para verificar qual é a colocação de cada Ifes no que diz respeito a transparência passiva das informações. Alvarenga (2017) afirma que o ranking leva em consideração três critérios que são analisados nas universidades federais: as solicitações de informação atendidas pela universidade, tempo médio para resposta e as prorrogações no prazo de atendimento às questões.

A coleta e análise da transparência passiva ocorreu de forma sequencial: etapa 1, com elaboração das perguntas com base nos resultados da análise de conteúdo da transparência ativa; etapa 2 com o envio das perguntas e espera pelas respostas no tempo determinado; etapa $3 \mathrm{com}$ análise das respostas com o checklist da EBT $360^{\circ}$; etapa 4 com considerações obtidas com o checklist da EBT $360^{\circ}$.

$\mathrm{Na}$ transparência ativa constam diversas categorias e subcategorias relacionadas as políticas de cotas, com base nelas, foram elaboradas as três perguntas apresentadas no apêndice A. Não houve um critério de escolha das modalidades para a elaboração das perguntas e buscou-se por elaborar as perguntas que atendessem as duas grandes categorias de uma forma mais ampla, sendo objetivas e claras, baseando-se na metodologia da EBT $360^{\circ}$ (2019), sendo enviadas para as Ifes pelo e-sic. Foram criados três cadastros diferentes no portal do e-sic - cidadão 1, cidadão 2 e cidadão 3 -, então, foram enviadas as perguntas para as Ifes, todas no mesmo dia. Após o envio das perguntas, o e-sic gerou um número de protocolo que auxiliou no acompanhamento das solicitações, transmitindo maior segurança e confiabilidade para os usuários. 
A partir da data do envio das perguntas, de acordo com a LAI no art. $11 \S 1^{\circ}$ o órgão ou entidade que receber o pedido deverá atendê-lo em prazo não superior a 20 dias e no $\S 2^{\circ}$ do mesmo art. 11 da LAl é afirmado que "o prazo referido no $\S 1^{\circ}$ poderá ser prorrogado por mais 10 (dez) dias, mediante justificativa expressa, da qual será cientificado o requerente.

A etapa 3 consistiu na análise das respostas das Ifes com o checklist da EBT $360^{\circ}$. Para realizar a análise das respostas das Ifes utilizou-se um checklist de análise da transparência passiva, o mesmo foi adaptado para o estudo em universidades, pois ele é utilizado para analisar a transparência ativa e passiva de prefeituras. O checklist da EBT $360^{\circ}$ conta com sete ordens que foram analisadas.

Após o retorno de todas as universidades e institutos federais, foi realizada a análise das respostas baseando-se no checklist da Escala Brasil Transparente - EBT $-360^{\circ}$ disponível no site da Controladoria Geral da União (2019).

\section{Análise dos resultados}

Apresenta-se, na seqüência, a análise da transparência ativa da informação, sendo que a mesma está composta de duas etapas: análise da categoria Sisu e análise da categoria política própria institucional. Em seguida será apresenta a análise da transparência passiva da informação, a qual utilizou a EBT $360^{\circ}$ como embasamento e suporte para apresentação e análise dos dados.

Transparência ativa: aplicação da análise de conteúdo

Visando analisar a transparência ativa nos sites das dez Ifes do Rio Grande do Sul no que se refere às políticas de cotas, foi realizada a coleta e análise dos materiais, elencando-se duas categorias, extraídas dos materiais analisados: a categoria 'Sisu' e a categoria 'Política própria institucional' que, de acordo com o quadro 1, estão divididas em subcategorias.

Quadro 1 -

Categorias, subcategorias e definições das Ifes para a transparência ativa.

\begin{tabular}{|c|c|c|c|}
\hline \multirow[t]{4}{*}{ Categoria } & Subc & Definição & Ifes \\
\hline & $\begin{array}{l}\text { Lei } \mathrm{n} \text {. } \\
12.711 / 2012\end{array}$ & $\begin{array}{lll}\text { Políticas de } & \begin{array}{l}\text { ingresso } \\
\text { em } \\
\text { instituições } \\
\text { federais }\end{array} \\
\text { ensino. } & & \end{array}$ & $\begin{array}{l}\text { Furg; Iffar; IFRS; Ifsul; } \\
\text { UFCSPA; UFFS; Ufpel; } \\
\text { Ufrgs; UFSM; Unipampa }\end{array}$ \\
\hline & Cursos & $\begin{array}{l}\text { Número de cursos e vagas } \\
\text { para cada curso na } \\
\text { instituição federal de ensino. }\end{array}$ & $\begin{array}{l}\text { Furg; Iffar; IFRS; Ifsul; } \\
\text { UFCSPA; UFFS; Ufpel; } \\
\text { Ufrgs; UFSM; Unipampa }\end{array}$ \\
\hline & $\begin{array}{l}\text { Cursos não } \\
\text { participantes }\end{array}$ & $\begin{array}{l}\text { Instituições que possuem } \\
\text { cursos que não participam } \\
\text { das políticas de ingresso do } \\
\text { Sisu. }\end{array}$ & $\begin{array}{l}\text { Furg; Ifsul; Ufrgs; UFSM; } \\
\text { Unipampa }\end{array}$ \\
\hline $\begin{array}{l}\text { Política } \\
\text { própria } \\
\text { institucional }\end{array}$ & $\begin{array}{l}\text { Processo } \\
\text { seletivo } \\
\text { específico }\end{array}$ & $\begin{array}{lcc}\text { Processo } & \text { seletivo } & \text { de } \\
\text { ingresso } & \text { próprio } & \text { da } \\
\text { instituição federal de ensino. }\end{array}$ & $\begin{array}{l}\text { Furg; Iffar; IFRS; Ifsul; } \\
\text { UFCSPA; UFFS; Ufpel; } \\
\text { Ufrgs; UFSM; Unipampa }\end{array}$ \\
\hline & $\begin{array}{c}\text { Ações } \\
\text { afirmativas das } \\
\text { Ifes }\end{array}$ & $\begin{array}{l}\text { Ações realizadas pelas } \\
\text { instituições para ingresso e } \\
\text { permanência dos candidatos. }\end{array}$ & $\begin{array}{l}\text { Furg; Iffar; IFRS; UFFS; } \\
\text { Ufpel; Ufrgs }\end{array}$ \\
\hline
\end{tabular}

Fonte: autores (2020). 
Conforme o quadro 1 observa-se que a categoria Sisu é composta por subcategorias denominadas lei n. 12.711/2012 (Lei de Cotas), cursos e vagas e cursos não participantes do Sisu. A categoria Política própria institucional está relacionada às ações de ingresso e permanência realizadas pelas próprias lfes, além daquelas relacionadas ao Sisu. Essa categoria está dividida em ações afirmativas das Ifes e processo seletivo específico. Cada categoria, nas suas subdivisões, apresenta modalidades que as integram.

\section{Análise da categoria Sisu}

No quadro 2 apresenta-se as modalidades que foram analisadas para a definição e composição das três subcategorias da categoria Sisu.

Quadro 2 -

Modalidades da categoria Sisu.

\begin{tabular}{|c|l|}
\hline Número & \multicolumn{1}{|c|}{ Modalidade } \\
\hline 1 & Ampla concorrência prataria igual ou inferior a 1,5 \\
\hline 2 & $\begin{array}{l}\text { Candidatos com renda familiar bruta per capita } \\
\text { salário mínimo que tenham cursado integralmente o ensino médio em } \\
\text { escolas públicas. }\end{array}$ \\
\hline 3 & $\begin{array}{l}\text { Candidatos autodeclarados pretos, pardos ou indígenas, com renda } \\
\text { familiar bruta per capita igual ou inferior a 1,5 salário mínimo e que } \\
\text { tenham cursado integralmente o ensino médio em escolas públicas. }\end{array}$ \\
\hline 4 & $\begin{array}{l}\text { Candidatos que, independente da renda tenham cursado } \\
\text { integralmente o ensino médio em escolas públicas. }\end{array}$ \\
\hline 5 & $\begin{array}{l}\text { Candidato autodeclarados pretos, pardos ou indígenas que, } \\
\text { independentemente da renda, tenham cursado integralmente o ensino } \\
\text { médio em escolas públicas. }\end{array}$ \\
\hline 6 & $\begin{array}{l}\text { Candidatos com deficiência que tenham renda familiar bruta per } \\
\text { capita igual ou inferior a 1,5 salário mínimo e que tenham cursado } \\
\text { integralmente o ensino médio em escolas públicas. }\end{array}$ \\
\hline 7 & $\begin{array}{l}\text { Candidatos com deficiência que, independentemente da renda, } \\
\text { tenham cursado integralmente o ensino médio em escolas públicas. }\end{array}$ \\
\hline 8 & $\begin{array}{l}\text { Candidatos com deficiência autodeclarados pretos, pardos ou } \\
\text { indígenas que, independentemente da renda, tenham cursado } \\
\text { integralmente o ensino médio em escolas públicas. }\end{array}$ \\
\hline 9 & Cursos e vagas \\
\hline 10 & Cursos não participantes do Sisu \\
\hline
\end{tabular}

Fonte: autores (2019).

De acordo com o quadro 2 observa-se que a subcategoria 'Sisu' é constituída de dez modalidades. As modalidades 1 a 8 estão relacionadas diretamente com a lei $n$. 12.711/2012 e foram agrupadas dentro de uma mesma subcategoria: Lei n. 12.711/2012).

As informações pertinentes às leis de cotas encontram-se no termo de adesão das Ifes. Observou-se que as Ifes apresentam diversas maneiras de chegar até o local que se encontra disponível o termo de adesão, cada uma com suas particularidades. A UFFS, Furg, UFCSPA, UFPel, UFSM e a Unipampa utilizam praticamente os mesmos passos 
Já o Ifsul e a Ufrgs apresentam outra maneira para disponibilizar o termo de adesão: criaram uma aba própria para o Sisu em que, ao clicar nesse ícone, o usuário é direcionado para os termos de adesão de diversos períodos. Vale ressaltar que essa iniciativa das Ifes facilitou a procura e o acesso dos documentos, sendo mais simples e ágil. O Iffar é a única Ifes que não disponibiliza o termo de adesão no site.

Se tratando da transparência ativa da informação, dentre as dez lfes, três - UFFS, IFRS e Ufrgs - se destacaram por possuir, além do termo de adesão, técnicas próprias para divulgar as informações referentes a disponibilidade das cotas para ingresso.

O IFRS também utiliza técnicas diferenciadas para divulgar as informações referentes às políticas de cotas. Além de conter as informações no termo de adesão, a possui uma aba própria para apresentar o sistema de cotas utilizado, é ilustrativo e autoexplicativo, as informações são claras e detalhadas. Utiliza métodos como texto escrito, infográficos informativos e explicativos, vídeos e editais na Língua Brasileira de Sinais que apresentam as políticas de cotas utilizadas e ainda auxiliam o candidato a encontrar a melhor opção para se inscrever. O IFRS conta com vídeos e editais em Libras, com informações claras e acessíveis. Outra técnica usada é a utilização de infográficos informativos. $O$ intuito desses infográficos é auxiliar e informar as pessoas sobre vagas existentes no IFRS, qual a vaga que o candidato está adequado e explicar as informações pertinentes às políticas de cotas de forma clara e simplificada, buscando demonstrar que está adequada às normas da lei 12.711/2012.

Outra instituição que se destacou devido à transparência ativa das informações sobre as modalidades da Lei de Cotas foi a Ufrgs, que conta com metodologia própria para divulgar e tornar públicas essas informações, sendo de fácil acesso e compreensão.

A segunda subcategoria referente à categoria Sisu refere-se aos cursos e vagas disponíveis nas Ifes participantes do Sisu, ou seja, está relacionada ao número de cursos e vagas ofertados por cada instituição de ensino nos períodos pertinentes do processo seletivo. Para essa subcategoria adotou-se a modalidade 9 do quadro 2 para ser analisada.

Observa-se, no quadro 2, que as dez lfes disponibilizam as informações relacionadas ao número de cursos e vagas ofertadas. Ao acessar os sites das Ifes é possível encontrar essas informações no termo de adesão de cada processo seletivo. Nos sites das Ifes estudadas as informações referentes aos cursos e vagas ofertados não são encontrados tão facilmente, ou seja, a pessoa que desejar saber algo a respeito dessa informação deverá procurar pelo site até encontrá-la, pois as informações não estão dispostas de forma visível, dificultando a pesquisa.

Nos sites de todas as instituições, com exceção do Iffar, o termo de adesão pode ser encontrado no menu/página inicial, na aba Ingresso, ou então na aba referente a graduação ou Sisu. Após essa etapa, é preciso pesquisar pela página até encontrar o termo de adesão pertinente ao período correspondente e desejado. No site do IFFAR, observa-se que existem duas formas de divulgação dos cursos e vagas disponíveis: na página inicial existe a aba cursos, ao clicar nessa aba, a pessoa é direcionada para outra página em que contém os cursos disponíveis, um breve relato sobre o curso e ainda, os campus que ofertam esses cursos, porém, não constam as informações referentes ao número de vagas ofertadas, nem as modalidades disponíveis para ingresso. 
Outro método para averiguar o número de cursos e vagas ofertadas nos campi do Iffar é pelo termo de adesão, porém, localizar o mesmo é difícil, não está disponível em local visível e encontrá-lo só foi possível utilizando a guia de pesquisa busca no portal, e mesmo assim, o pesquisador é direcionado para uma página em que apresenta diversas opções e deve realizar uma busca mais detalhada até encontrar o termo de adesão que dispõe das informações referentes aos cursos e vagas.

A terceira subcategoria que compõe a categoria Sisu é denominada 'cursos não participantes do Sisu', ou seja, diz respeito às Ifes que possuem cursos que não utilizam o Sisu como método de ingresso. Observa-se no quadro 2, que cinco Ifes possuem cursos não participantes do Sisu: a Furg, Ifsul, Ufrgs, UFSM e Unipampa. Ao ser realizada a coleta dos dados nos sites dessas Ifes observou-se que as informações pertinentes a essa modalidade se encontram também no termo de adesão.

Em relação à transparência ativa dessas informações, constata-se que as Ifes apresentam de forma clara os pontos relacionados aos cursos não participantes do Sisu, porém, apenas citam os cursos e não apresentam mais detalhes a respeito do assunto. Com isso existe uma deficiência no cumprimento do art. $4^{\circ}$ inciso IX, da LAI, o qual indica ser imprescindível a primariedade: qualidade da informação coletada na fonte, com o máximo de detalhamento possível, sem modificações.

\section{Análise da categoria política própria institucional}

A análise da categoria política própria institucional é composta por duas subcategorias: processo seletivo específico da instituição, que está relacionado ao método de ingresso criado e utilizado, e, ações afirmativas das Ifes, realizadas com vistas a ingresso e permanência dos candidatos nas lfes.

Além do Sisu as Ifes contam com processos seletivos específicos de ingresso. Todas as dez Ifes do estudo contam com processo seletivo próprio, cada uma com suas particularidades, buscando atender a todos os estudantes. Algumas mantém processos seletivos em comum, sendo os mais comuns os processos seletivos EAD e transferência/retorno. Destaca-se também que o Iffar apresenta o maior número de processos seletivos próprios, contando com cinco tipos diferentes, além do Sisu.

No que diz respeito à transparência ativa dessas informações pode-se afirmar que encontrar os editais e informações referentes à documentação necessária para ingresso, cotas existentes em cada processo seletivo, entre outras informações, encontram-se em locais de fácil acesso, sendo visíveis e claros. As Ifes estão atendendo os requisitos disponíveis na LAI no que diz respeito à disponibilidade de qualidade da informação que pode ser conhecida e utilizada por indivíduos, equipamentos ou sistemas autorizados, levando em consideração que as informações são acessíveis e claras. O IFRS conta com um portal específico, voltado unicamente para os processos seletivos, disponibilizando todas as informações a respeito desses métodos de ingresso.

No que diz respeito à política própria institucional, a outra modalidade que foi analisada nos sites das Ifes foram as ações afirmativas específicas. Nem todas as Ifes do estudo contam com ações afirmativas próprias, como a UFCSPA e o Ifsul. Com relação à transparência ativa das informações relacionadas às ações afirmativas, podese determinar que as Ifes apresentam de forma acessível e clara as informações pertinentes à cada ação afirmativa. Dessa forma, estão adequadas ao art. $4^{\circ}$, inciso $\mathrm{VI}$ da 
LAI. As informações relacionadas as ações afirmativas na UFSM e na UFCSPA são difíceis de encontrar, sendo necessária uma pesquisa mais demorada e detalhada até localizá-las.

Transparência passiva: adaptação da EBT

Todas as Ifes responderam às perguntas dentro do prazo determinado por lei: vinte dias mais dez dias. Em relação ao prazo levou-se em consideração também a metodologia da EBT $360^{\circ}$ (2019), que propõem que respostas recebidas em até 34 dias após o envio do pedido é considerado dentro do prazo. Esse prazo é estimado levando em consideração a possibilidade de o prazo coincidir com feriados ou dias não úteis.

Para realizar a análise das respostas das Ifes utilizou-se o quadro 3 , no qual se apresenta um checklist de análise da transparência passiva. De acordo com a CGU (2019), a resposta sim gera pontuação máxima do quesito e a resposta não gera pontuação zero. 
Quadro 3 -

Checklist da EBT $360^{\circ}$ para as dez Ifes do estudo.

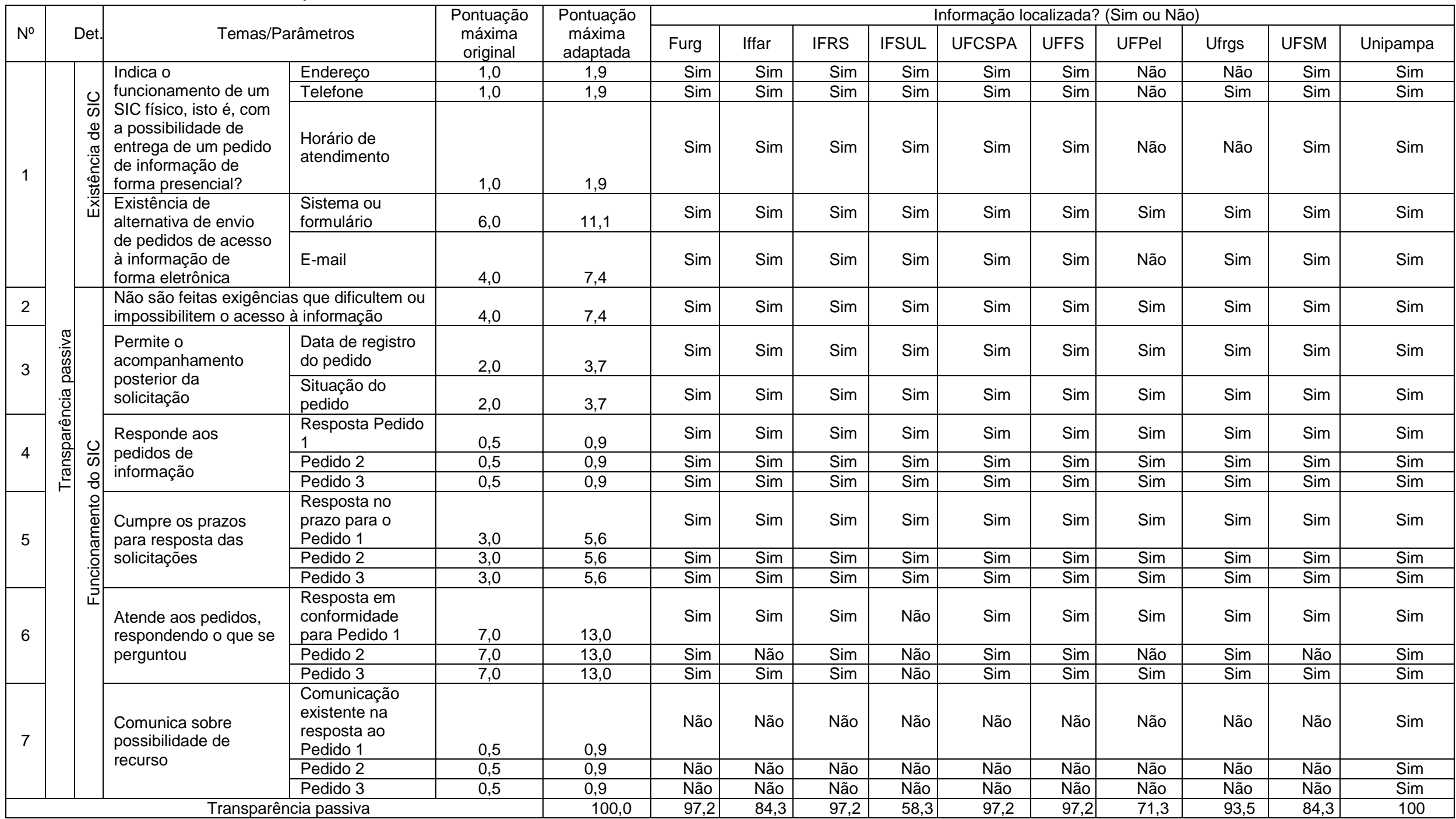

Fonte: autores (2020).

\begin{tabular}{|l|l|l|l|l|l|}
\hline Regae: Rev. Gest. Aval. Educ. & Santa Maria & v. 9 & n. 18 & Pub. contínua 2020 & p. 1-17 \\
\hline
\end{tabular} 
De acordo com Alvarenga (2018) a Furg encontra-se na $41^{\text {a }}$ colocação no ranking da transparência das universidades federais do Brasil. Com relação a transparência passiva das informações a Furg atingiu uma nota de $97,2 \%$ e percebeu-se que ela atende à todas as ordens, com exceção da ordem 7 , pois não disponibilizou informações referentes as possibilidades de os cidadãos entrar com recurso em caso de não cumprimento dos prazos previstos na LAI. Porém, a Furg obteve uma nota satisfatória, demonstrando que atendeu as dúvidas relacionadas às políticas de cotas e suas aplicabilidades como método de ingresso na instituição.

A pontuação que o Iffar recebeu foi de $84,3 \%$, isso se dá pelo fato de que o pedido do Cidadão 2 não foi respondido, ou seja, não foi atendido o que foi solicitado sobre às políticas de cotas. Outro ponto que o Iffar recebeu nota negativa foi na ordem 7 , que se refere sobre a possibilidade de o usuário entrar com recurso em caso de não haver respostas.

O checklist realizado com o IFRS demonstrou uma pontuação máxima de 97,2\%. Tratando-se da transparência passiva das informações referentes às políticas de cotas é perceptível que o IFRS buscou atender a todas as dúvidas enviadas nos três casos, apresentando as informações de forma clara e acessível em ambos os casos, respondendo dentro do tempo determinado pela LAI, disponibilizando-se para esclarecer possíveis dúvidas com relação as respostas. Porém, o IFRS não informou sobre a possibilidade de o cidadão entrar com recurso em caso de não receber a resposta.

No checklist realizado no Ifsul é perceptível que a instituição apresentou notas negativas em diversos pontos. Nos três cidadãos as respostas não estavam de acordo com as perguntas enviadas ou não condiziam com a pergunta enviada. $O$ Ifsul apresentou uma nota de $58,3 \%$, sendo que nas ordens 6 e 7 não foram localizadas as respostas para as perguntas enviadas.

O checklist realizado na UFCSPA demonstra que foram localizadas as informações sobre o que foi solicitado, com exceção da ordem 7, pois a mesma não comunicou sobre a possibilidade de recurso em nenhuma das perguntas enviadas. A UFCSPA atingiu uma nota máxima de 97,2\%. De acordo com Alvarenga (2018) a UFCSPA encontra-se na $22^{a}$ colocação no ranking da transparência das universidades federais do Brasil, no que diz respeito a transparência das informações.

O checklist realizado com a UFFS demonstra que todas as informações foram localizadas, com exceção das respostas da ordem 7, pois a UFFS não informou para nenhum dos três cidadãos a possibilidade de entrar com recurso. A nota máxima que a instituição atingiu foi 97,2\%. Percebe-se que a UFFS buscou atender a todas as informações solicitadas pelos três cidadãos, enviando respostas claras e compreensíveis que esclareceram as dúvidas relacionadas às políticas de cotas utilizadas.

Para Silva e Vacovski (2015) a ideia de transparência de informação implica em colocar à disposição das pessoas as informações necessárias e suficientes para que os cidadãos possam participar, discutir e opinar sobre a implementação de políticas públicas, além de exigir o cumprimento das mesmas. Com isso, percebe-se que a UFFS além de cumprir com as exigências legais impostas pela LAl, visa a atender as necessidades das pessoas, objetivando responder as dúvidas em uma linguagem informal, para que todos possam compreender as informações que estão sendo disponibilizadas. 
Alvarenga (2017) afirma que a UFFS ficou em primeiro lugar no que diz respeito a transparência passiva das informações do Ranking da Transparência das Universidades Federais no ano de 2017, já no ano de 2018 a UFFS ficou em 4lugar, perdendo a primeira colocação para a Universidade Federal do Cariri, localizada no sul do Ceará.

Por meio do checklist realizado na Ufpel notou-se que a mesma apresentou diversos pontos negativos, obtendo $71,3 \%$ como nota final. Alvarenga (2018) demonstrou que a Ufpel ficou no $35^{\circ}$ lugar no Ranking da Transparência das Universidades Federais do Brasil. $\mathrm{Na}$ ordem 1 do checklist realizado na Ufpel foram encontradas informações apenas no item relacionado a existência de sistema ou formulário do SIC. Não foram localizadas informações a respeito do pedido do cidadão 2 referentes às políticas de cotas. Outro ponto negativo refere-se à ordem 7 , pois a Ufpel não informou sobre a possibilidade de recurso.

A nota máxima atingida pela Ufrgs foi de $93,5 \%$, sendo que as informações não foram localizadas em alguns pontos da ordem 1 e na ordem $7 \mathrm{em}$ sua totalidade. Alvarenga (2018) indica que a Ufrgs ficou posicionada no $53^{\circ}$ lugar no ranking da transparência das universidades federais do Brasil. Na ordem 1 não foram encontradas informações referentes ao endereço e horário de atendimento de um SIC físico para atender as pessoas e esclarecer possíveis dúvidas sobre a Ufrgs, os processos seletivos, políticas de cotas e todas as atividades relacionadas com a mesma. Na ordem 7 não foram localizadas informações, pelo fato de a Ufrgs não comunicar sobre a possibilidade de recurso em nenhum dos três pedidos.

O checklist realizado na UFSM mostra que a mesma obteve uma nota máxima de $84,3 \%$, levando em consideração o fato de que o cidadão 2 não obteve resposta de acordo com o que foi solicitado, ou seja, não foram localizadas as informações referentes ao atendimento do pedido referente às políticas de cotas. Nota-se que na ordem 7 não foram localizadas as informações, pois a UFSM não informou sobre a possibilidade de entrar com recurso. De acordo com Alvarenga (2018), a UFSM ficou em $48^{\circ}$ lugar no ranking da transparência das universidades federais do Brasil.

A UFSM obteve negatividade nas ordens 4,6 e 7 , sendo que a pergunta enviada pelo cidadão 2 não foi atendida corretamente e a mesma não informou sobre a possibilidade de entrar com recurso caso o pedido não seja atendido. Porém, percebe-se que a UFSM procura responder a maior parte das solicitações e disponibilizar todos os dados referentes ao SIC físico.

O checklist realizado na Unipampa, baseando-se nas respostas recebidas e na análise do portal, demonstrou que a mesma obteve nota máxima de $100 \%$ no que diz respeito a transparência passiva das informações. Alvarenga (2018) informa que a Unipampa ficou em $30^{\circ}$ lugar no ranking da transparência das universidades federais do Brasil, pois na pesquisa realizada pelo autor a mesma não atendeu a todos os pedidos enviados. A Unipampa foi a única instituição do estudo que obteve a nota máxima, pois somente nela foi possível localizar as informações solicitadas em todas as ordens do checklist da EBT $360^{\circ}$.

Ressalta-se que a Unipampa se preocupou em disponibilizar, nos três casos, as informações sobre a possibilidade de os cidadãos entrarem com recurso, se houvesse necessidade, apresentando as exigências impostas pela LAI de maneira clara e compreensível. Sendo assim, Figueiredo e Santos (2013) afirmam que a compreensão das 
informações que estão sendo expostas é fundamental para o público assimilar o que está sendo apresentado, podendo assim, minimizar as dúvidas sobre as informações disponibilizadas.

\section{Considerações finais}

Com este estudo objetivou-se analisar a transparência ativa e passiva da informação relacionada às políticas de cotas nos sites das universidades e institutos federais de ensino superior do Rio Grande do Sul. Ao realizar a análise da transparência ativa das informações relacionadas às políticas de cotas das lfes estudadas, observou-se que algumas destacavam-se na divulgação das informações, como é o caso da UFFS, IFRS e UFRGS, as quais buscam adotar diversas maneiras de divulgar as informações, de modo que todos possam conseguir ter acesso e entendê-las.

Observou-se que as Ifes procuram deixar as informações sobre as políticas de cotas nos sites acessíveis, contando com ícones e abas explicativas a respeito do que está sendo pesquisado. Ressalta-se que as Ifes atendem à Lei Brasileira de Inclusão da Pessoa com Deficiência, que tornou obrigatória a acessibilidade nos sítios da internet dos órgãos públicos, pois, contam com o sistema Vlibras, capaz de atender as pessoas com necessidades especiais que procuram por informações.

No que diz respeito à transparência passiva das informações, a FURG, IFRS, UFCSPA e a UFFS se destacaram por obter $97,2 \%$ como nota máxima referente ao fornecimento de informações. A Unipampa atingiu 100\%, ao atender a todos os quesitos. Já o IFSUL se destacou por ter a menor nota, 55,6\%, vale lembrar que obteve essa nota pelo fato de as respostas não eram condizentes com as perguntas.

Em ambos os casos, no que se referem à transparência ativa e passiva das políticas de cotas, as Ifes apresentaram pontos positivos e negativos. Como pontos positivos pode-se citar o fato de preocupam-se em atender as exigências da LAI, apresentar e fornecer as informações em uma linguagem mais informal e clara, a maioria das Ifes disponibilizam as informações sobre as cotas em locais acessíveis, dentre outros pontos positivos. Apresentaram também alguns pontos negativos, como o fato das constantes atualizações dos sites dificultarem a procura pelas informações referentes às políticas de cotas, uma vez que em alguns casos ambos são trocados de lugar nos sites, a opção busca no portal raramente disponibiliza aquilo que foi solicitado, dificultando a procura.

Porém, é perceptível que as Ifes procuram atender as exigências da lei, divulgando e fornecendo as informações, tornando-as acessíveis para todas as pessoas, disponibilizandose para auxiliar as pessoas a respeito das informações desejadas, de forma clara, procurando atender as necessidades das pessoas.

Para a realização do estudo foram encontradas algumas limitações, sendo que a que mais dificultou as coletas e análises dos dados foi a constante atualização dos sites das Ifes, pois as informações que já tinham sido localizadas acabavam trocando de lugar, necessitando realizar uma nova busca.

Como sugestão para estudos futuros destaca-se a possibilidade de realizar a mesma pesquisa, porém, voltada somente para institutos federais, pois os mesmos apresentam particularidades em relação às universidades federais, e nessa pesquisa 
foram tratados de forma igualitária. Sugere-se, também, realizar um estudo a compreensão acerca do conhecimento dos cidadãos em relação às políticas de cotas e as leis de transparência e acesso à informação pública.

\section{Referências}

ALVARENGA, Cristiano. Ranking da transparência das universidades federais 2017. 2017. Disponível em https://cristianoalvarenga.com/pesquisa/ranking-da-transparencia-dasuniversidades-federais-2017. Acesso em 19 set. 2019.

ALVARENGA, Cristiano. Ranking da transparência das universidades federais 2018. 2018. Disponível em https://cristianoalvarenga.com/pesquisa/ranking-da-transparencia-2018. Acesso em 19 set. 2019.

ASSUNÇÃO, Amanda Vanessa Pereira de; SANTOS, Catarina de Almeida; NOGUEIRA, Danielle Xabregas Pamplona. Política de cotas raciais na UnB: um estudo sobre o acesso de negros na universidade durante o período 2004 a 2012. Revista HISTEDBR On-line, Campinas, n. 1, v. 18, 2018, p. 212-233.

BARDIN, Lourence. Análise de conteúdo. São Paulo: Edições 70, 2011.

BRASIL. Lei complementar n. 13.146, de 6 de julho de 2015. Brasília: Presidência da 2015.

Disponível

http://www.punf.uff.br/inclusao/images/leis/lei 13146.pdf. Acesso em 23 set. 2019.

BRASIL. Lei n. 12.711, de 29 de agosto de 2012. Brasília: Presidência da República, 2012. Disponível em http://www.planalto.gov.br/ccivil 03/ ato2011-2014/2012/lei/l12711.htm. Acesso em 10 abr. 2019.

BRASIL. Lei n. 12.527, de 18 de novembro de 2011: lei de acesso à informação. Brasília: Presidência da República, 2011. Disponível em http://www.planalto.gov.br/ccivil 03/ ato2011-2014/2011/lei//12527.htm. Acesso em 9 abr. 2019.

BUCCI, Maria Paula Dallari (org.). Políticas públicas: reflexões sobre o conceito jurídico. São Paulo: Saraiva, 2006.

CARVALHO, José Jorge de. Usos e abusos da antropologia em um contexto de tensão racial: o caso das cotas para negros na UnB. 2005. Horizontes Antropológicos, Porto Alegre, v. 11, n. 23, 2005, p. 237-246.

CONTROLADORIA GERAL DA UNIÃO. Metodologia e critérios de avaliação EBT $360^{\circ}$. Disponível em https://www.cgu.gov.br/assuntos/transparencia-publica/escala-brasiltransparente-360/arquivos/metodologia-ebt v1.pdf. Acesso em 30 maio 2019.

CONTROLADORIA GERAL DA UNIÃO. Manual da lei de acesso à informação para Estados e Municípios. Brasília, 2013. Disponível em https://www.cgu.gov.br/Publicacoes/transparencia-publica/brasiltransparente/arquivos/manual lai estadosmunicipios.pdf. Acesso em 5 maio 2019.

FARACO, Bruno Pereira. Transparência das informações públicas nos portais das instituições federais de educação profissional da região sul do Brasil. Curitiba: UFTPR, 2015. 123f. Dissertação (Mestrado em Planejamento e Governança Pública). Programa de PósGraduação em Planejamento e Governança Pública, Universidade Tecnológica Federal do Paraná. 
FIGUEIREDO, Vanuza da Silva; SANTOS, Waldir Jorge Ladeira dos. Transparência e controle social na administração pública. Temas de Administração Pública, Araraquara, v. 8, n. 1, 2013, p. 1-20.

MAGALHÃES, Wallace Lucas. A lei do boi e a relação entre educação e propriedade: o caso da universidade federal rural do rio de janeiro. Tempos Históricos, Rio de Janeiro, v. 21, n. 2, 2017, p. 434-464.

MAGNONI, Maria Salete. Lei de cotas e a mídia brasileira: o que diria Lima Barreto? Estudos Avançados, São Paulo, v. 30, n. 87, 2016, p. 299-312.

MENEZES, Paula Dutra Leão de. Reflexão sobre o sistema de cotas no Brasil. Revista Lugares de Educação, Bananeiras, v. 5, n. 11, 2015, p. 147-160.

OLIVEN, Arabela Campos. Ações afirmativas, relações raciais e política de cotas nas universidades: uma comparação entre os Estados Unidos e o Brasil. Revista Brasileira de Educação, Porto Alegre, v. 30, n. 1, 2007, p. 29-51.

PEREIRA, Andressa Braga; RODRIGUES, Eliane; GUILHERME, Rosilaine Coradini. Ações afirmativas: política de cotas raciais para o ingresso nas universidades públicas. Revista Textos e Contextos, Porto Alegre, v. 9, n. 2, 2010, p. 244-250.

PIRES, Atrícia Menezes; SCHERER, Flavia Luciane; SANTOS, Marindia Brachak dos; CARPES, Aletéia de Moura. Transparência da gestão pública municipal: um estudo dos municípios de Santa Maria e Novo Hamburgo/RS. Revista Estudos do Cepe, Santa Cruz do Sul, n. 38, 2013, p. 131-160.

RODRIGUES, Georgete Medleg. Indicadores de transparência ativa em instituições públicas: análise dos portais de universidades públicas federais. Liinc em Revista, Rio de Janeiro, v. 9, n. 2, 2013, p. 423-438.

SILVA, Rosane Leal da; $\mathrm{HOCH}$, Patrícia Adriani; RIGHI, Lucas Martins. Transparência pública e atuação normativa do CNJ. Revista de Direito do GV, São Paulo, v. 9, n. 2, 2013, p. 489-514.

SILVA, Dina Carla Vasconcelos Sena da; VACOVSKI, Eduardo. A transparência na administração pública como instrumento facilitador para o controle social. Caderno Gestão Pública, Curitiba, v. 7, n. 4, 2015, p. 67-86.

SOARES, Fabiana de Menezes; JARDIM, Tarciso Dal Maso; HERMONT, Thiago Brazileiro Vilar. Acesso à informação pública: uma leitura da lei n. 12.527, de 18 de novembro de 2011. Brasília: Senado Federal, 2013.

SOUZA, Boaventura de. Igualdade e discriminação à luz das políticas de ações afirmativas. SEMINÁRIO ARTE, EDUCAÇÃO E RELAÇÕES ETNICORRACIAIS, 1, 2014. Anais ... Rio de Janeiro: Cefet/RJ, 2014. Disponível em https://nelsonjoaquim.jusbrasil.com.br/artigos/169385896/igualdade-e-discriminacao-a-luzdas-politicas-de-acoes-afirmativas. Acesso em 25 jun 2019.

SOUZA, Letícia Pereira. PORTES, Écio Antônio. As propostas de políticas/ações afirmativas das universidades públicas e as políticas/ações de permanência nos ordenamentos legais. Revista Brasileira Estudos Pedagógicos, Brasília, v. 92, n. 232, 2011, p. 516-541.

VENTURA, Kátia Santiago; SIEBRA, Sandra de Albuquerque. E-acessibilidade na transparência ativa: a aplicação das tecnologias para implementação da Lei de Acesso à Informação. Informação \& Tecnologia (ITEC), Marília, v. 2, n. 2, 2015, p. 71-87. 
Itiane Vanessa Adamski é graduada em Administração pela Universidade Federal da Fronteira Sul, Campus Cerro Largo.

Orcid: https://orcid.org/0000-0003-4609-5108.

Endereço: Avenida Jacob Reinaldo Haupenthal, 1580 - 97900-000 - Cerro Largo - RS Brasil.

E-mail: itianeadamski@hotmail.com.

Monize Sâmara Visentini é professora adjunta na Universidade Federal da Fronteira Sul, campus Cerro Largo.

Orcid: https://orcid.org/0000-0001-6233-6106.

Endereço: Avenida Jacob Reinaldo Haupenthal, 1580 - 97900-000 - Cerro Largo - RS Brasil.

E-mail: monize.visentini@uffs.edu.br.

Darlan Nei Writzl é estudante do curso de Administração na Universidade Federal da Fronteira Sul, campus Cerro Largo.

Orcid: https://orcid.org/0000-0003-0341-1625.

Endereço: Avenida Jacob Reinaldo Haupenthal, 1580 - 97900-000 - Cerro Largo - RS Brasil.

E-mail: darlan.writzl@outlook.com.

Recebido em 4 de abril de 2020.

Aceito em 21 de julho de 2020.

(c) $(1) \Theta \Theta$ 